\title{
The flow characteristics of superplasticity
}

\author{
M. Kawasaki ${ }^{1,2 \dagger}$, R. B. Figueiredo ${ }^{3}$, T. G. Langdon ${ }^{2,4}$ \\ ${ }^{\dagger}$ megumi@hanyang.ac.kr \\ ${ }^{1}$ Division of Materials Science and Engineering, Hanyang University, 133-791, Seoul, South Korea \\ ${ }^{2}$ Departments of Aerospace \& Mechanical Engineering and Materials Science, University of Southern California, \\ Los Angeles, CA 90089-1453, USA CA 90089-1453, Los Angeles, USA \\ ${ }^{3}$ Department of Materials Engineering and Civil Construction, Universidade Federal de Minas Gerais, Belo Horizonte \\ 31270-901, MG, Brazil \\ ${ }^{4}$ Materials Research Group, Faculty of Engineering and the Environment, University of Southampton, \\ SO171BJ, Southampton, U.K
}

Attaining superplastic elongations is an important prerequisite for using metals in commercial superplastic forming applications. This review briefly summarizes the principles of superplasticity in conventional materials and then demonstrates that similar behavior, for both the flow properties and the cavitation characteristics, may be attained in ultrafine-grained materials with submicrometer grain sizes produced through the application of severe plastic deformation (SPD). An advantage of using SPD processing is that the regime of superplastic flow is displaced to faster strain rates and often occurs within the region of high strain rate superplasticity.

Keywords: cavitation, flow mechanisms, grain boundary sliding, severe plastic deformation, superplasticity.

\section{Introduction}

Superplasticity refers to the exceptionally high elongations that may be attained in a limited number of polycrystalline materials when they are pulled in tension. In practice, the ability to achieve very high strains in tension provides the capability of using this material in commercial superplastic forming operations in which sheet metals are formed into complex shapes and curved forms that are used in a wide range of applications from aerospace and automotive to architectural and in the production of many consumer products [1].

In order to describe the characteristics of superplastic flow, it is first necessary to give a formal definition of superplasticity. This was defined in the following way in an earlier detailed review [2]:

«Superplasticity is the ability of a polycrystalline material to exhibit, in a generally isotropic manner, very high elongations prior to failure. The measured elongations in superplasticity are generally at least $400 \%$ and the measured strain rate sensitivities are close to $\sim 0.5$.»

From a historical perspective, there are several reports of reasonably high tensile elongations in a number of metals in the early part of the twentieth century but the first report of a true superplastic elongation occurred eighty years ago, in 1934, with a description of a Bi-Sn eutectic alloy which was extruded, aged for 7 days and then pulled at room temperature to a total elongation of $1950 \%$ when testing under a constant stress of $\sim 1.7 \mathrm{MPa}$ : the sample used in these experiments is shown in fig. 1 where it is coiled for easy photography [3]. More recently, much higher superplastic elongations have been reported including a record-breaking $7550 \%$ in a $\mathrm{Pb}$ $62 \%$ Sn eutectic alloy [4].
The objective of this report is to provide a brief overview of recent developments in superplasticity with a special emphasis on the flow properties.

\section{The flow mechanism in superplasticity}

In order to obtain an understanding of superplasticity, it is first necessary to identify the fundamental flow mechanism and then to derive the characteristics of this mechanism in terms of a rate-controlling relationship that may be used to accurately describe and predict the flow behavior. It is now recognized that superplasticity occurs through the process of grain boundary sliding (GBS) in which the individual grains of the polycrystalline matrix move over each other without incurring any significant dimensional changes [5]. In practice, it has been established that superplasticity requires a very small grain size and specifically a grain size which is smaller than the equilibrium subgrain size [6]. This means that subgrain boundaries are not formed within the grains in superplastic flow so that the sliding is accommodated by dislocation slip where dislocations move across the grains and then pile-up and climb into the opposing grain boundaries. There is direct experimental evidence supporting the occurrence of intragranular slip during superplastic flow [7-10].

Two fundamental requirements must be fulfilled in order to achieve superplasticity [11]. First, the grain size of the material must be very small and typically less than $\sim 10 \mu \mathrm{m}$. Second, since superplasticity is a diffusion-controlled process, the testing temperature must be above $\sim 0.5 T_{\mathrm{m}}$ where $T_{\mathrm{m}}$ is the absolute melting temperature of the material.

For all flow processes at elevated temperatures, the steadystate strain rate, $\dot{\mathcal{E}}$, may be expressed by a relationship of the form $[11-13]$ 


$$
\dot{\varepsilon}=\frac{A D G \mathbf{b}}{k T}\left(\frac{\mathbf{b}}{d}\right)^{p}\left(\frac{\sigma}{G}\right)^{n}
$$

where $A$ is a dimensionless constant, $D$ is the appropriate diffusion coefficient, $G$ is the shear modulus, $\mathbf{b}$ is the Burgers vector, $k$ is Boltzmann constant, $T$ is the absolute temperature, $d$ is the grain size, $\sigma$ is the applied stress and $p$ and $n$ are the exponents of the inverse grain size and the stress, respectively. By modeling superplasticity as a process in which GBS is accommodated by intragranular slip, it can be shown that the steady-state strain rate is given by eq. (1) with $n=2, p=2$, $D=D_{g b}$ where $D_{g b}$ is the coefficient for grain boundary diffusion and $A \approx 10$ [14].

The stress exponent, $n$, is directly related to the strain rate sensitivity, $m$, because $n=1 / m$ and it was shown in very early work that the elongations achieved in tensile testing are directly related to the measured values of $m$ [15]. This early plot is shown in fig.2 [11] and it also includes experimental data for the $\mathrm{Zn}-22 \% \mathrm{Al}$ eutectoid alloy [16] and the Pb-62\% Sn eutectic alloy [17] where $\Delta L / L_{o} \%$ denotes the percentage change in length with respect to the original length of the sample, $L_{o}$. Thus, it is apparent from fig. 2 that high elongations require high values of $m$ and typically these values are of the order of $m \approx 0.5$ which corresponds to $n \approx 2$ in eq. (1). It is important to note that this is also consistent with the theoretical model for GBS in superplasticity and it directly confirms the potential for achieving very high elongations when the strain rate sensitivity has a value of $\sim 0.5$.

\section{The fundamental principles of superplasticity in metals}

An example of the experimental results obtained in tensile testing of a typical superplastic material is given in fig. 3 for the $\mathrm{Zn}-22 \% \mathrm{Al}$ eutectoid alloy having a grain size of $2.5 \mu \mathrm{m}$ tested at temperatures from 423 to $503 \mathrm{~K}$ : the upper plot shows the elongations to failure plotted against the initial strain rate for each specimen and the lower plot shows the variation of flow stress with the strain rate [16]. Each sample was pulled to failure and it is readily apparent that the elongations to failure vary with strain rate such that the

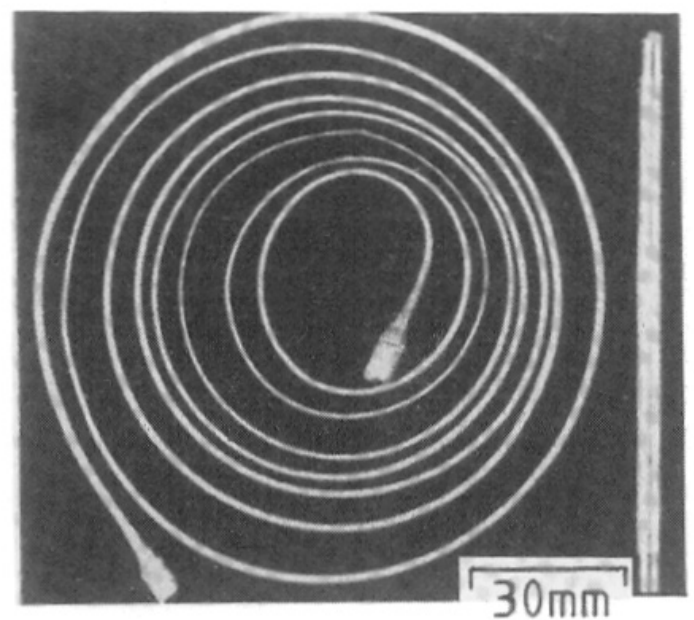

Fig. 1. A Bi-Sn alloy showing an elongation of $1950 \%$ as reported in 1934 by Pearson [3].

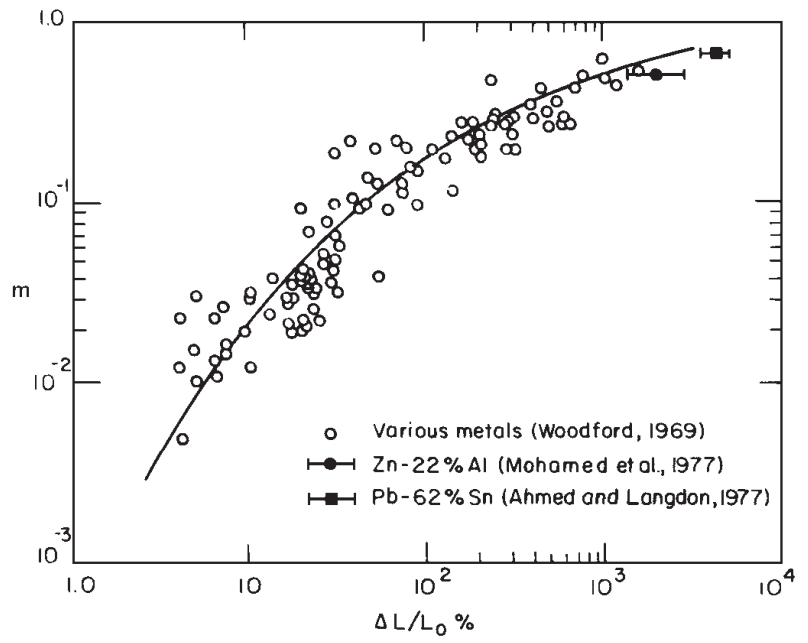

Fig. 2. Variation of the strain rate sensitivity, $m$, with the elongation to failure as reported originally by Woodford [15] with additional points for the $\mathrm{Zn}-22 \% \mathrm{Al}$ eutectoid alloy [16] and the $\mathrm{Pb}-62 \% \mathrm{Sn}$ eutectic alloy [17].

elongations are high, and up to $>2000 \%$, at intermediate strain rates whereas the elongations are significantly lower at both slower and faster strain rates. This result is consistent with a very early report demonstrating the occurrence of three separate regions of flow [18] where region I is not superplastic at the lowest strain rates, region II corresponds to superplastic flow at intermediate strain rates and region III again represents non-superplastic flow at the fastest strain rates. Furthermore, the experimental strain rate sensitivity is $m \approx 0.5$ in region II which matches the theoretical model whereas in regions I and III the strain rate sensitivities are $m \approx 0.2$ which corresponds to $n \approx 5$ and this is consistent with control by a conventional dislocation climb process [19].

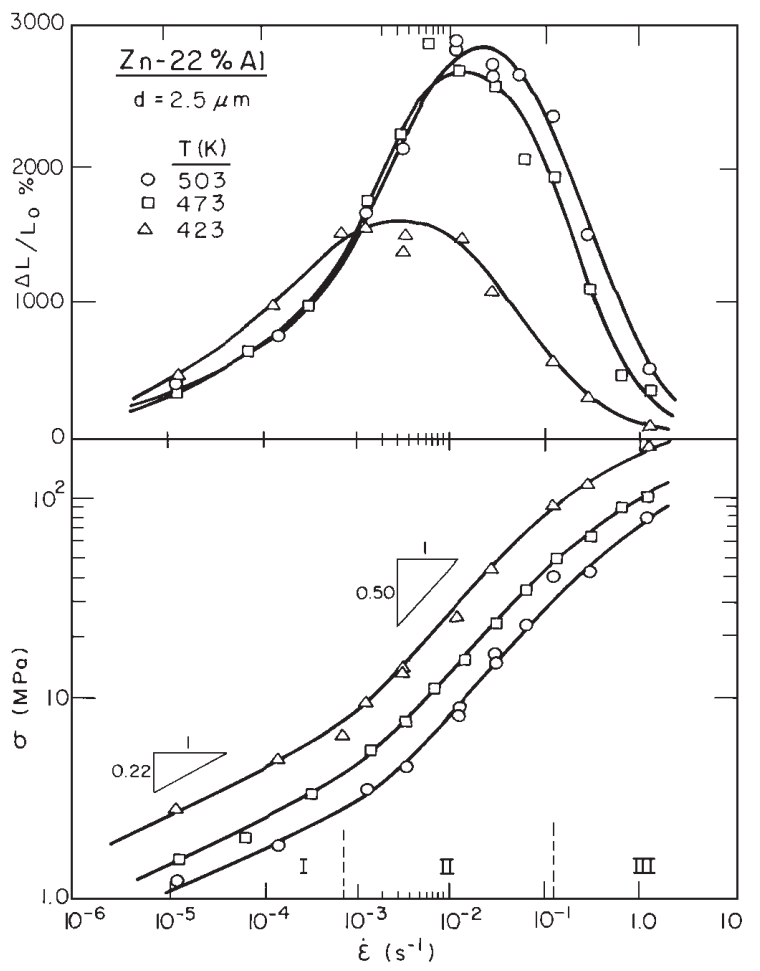

Fig. 3. Elongation to failure (upper) and flow stress (lower) versus the initial strain rate for the $\mathrm{Zn}-22 \% \mathrm{Al}$ eutectoid alloy showing the three regions of flow associated with superplasticity [16]. 
A considerable interest has developed over the last two decades in the processing of materials through the application of severe plastic deformation (SPD) where these processes introduce high dislocation densities and lead to significant grain refinement to the submicrometer or even the nanometer range [20-22]. In practice, various SPD techniques have been developed to produce ultrafine-grained (UFG) materials but the most developed and most promising procedures are equal-channel angular pressing (ECAP) [23] and high-pressure torsion (HPT) [24]. Inspection of eq. (1) shows that superplasticity may be achieved at high strain rates in materials having a UFG microstructure.

There are several reports to date evaluating the significance of GBS in UFG materials processed by ECAP. For example, GBS was observed in an Al-1421 alloy after ECAP for 12 passes [25] and in a $\mathrm{Zn}-22 \% \mathrm{Al}$ eutectoid alloy after 8 passes of ECAP [26] where both materials were tested at high temperatures within the limited range of strain rates from $1.0 \times 10^{-2}$ to $1.0 \times 10^{-1} \mathrm{~s}^{-1}$. Thereafter, a detailed investigation was conducted to provide details of the role of GBS using a $\mathrm{Zn}-22 \% \mathrm{Al}$ alloy having an initial grain size of $\sim 1.8 \mu \mathrm{m}[27,28]$. The alloy was processed by ECAP for 8 passes at $473 \mathrm{~K}$ to give a grain size of $\sim 0.8 \mu \mathrm{m}$ and tensile testing demonstrated that a highest elongation of $\sim 2230 \%$ was recorded in region II at a strain rate of $1.0 \times 10^{-2} \mathrm{~s}^{-1}$. This is within the regime of high strain rate superplasticity which is defined as superplastic elongations occurring at and above a strain rate of $10^{-2} \mathrm{~s}^{-1}$ [29]. It should be noted that there was no significant development in the superplastic properties in the $\mathrm{Zn}-\mathrm{Al}$ alloy having smaller grain sizes after ECAP and this is due to the formation of agglomerates of the same types of grains in the alloy after SPD processing [28].

A clear appearance of GBS was observed in the Zn$22 \% \mathrm{Al}$ alloy after ECAP, especially at the strain rate demonstrating the highest ductility in the superplastic region II $[27,28]$, and fig. 4 shows the microstructure on the polished surface within the gauge length of the sample pulled to an

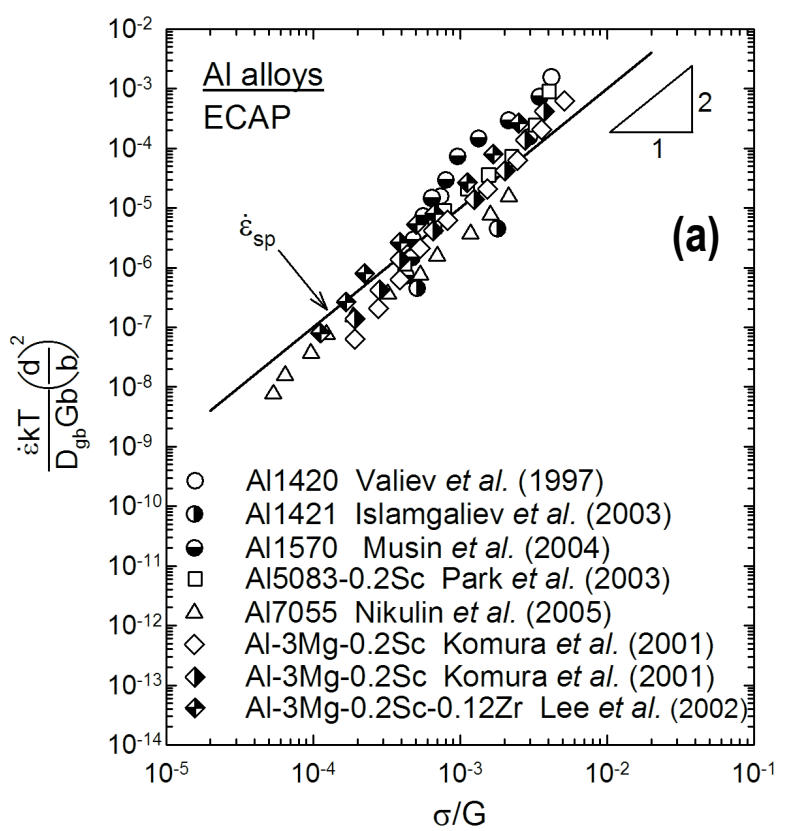

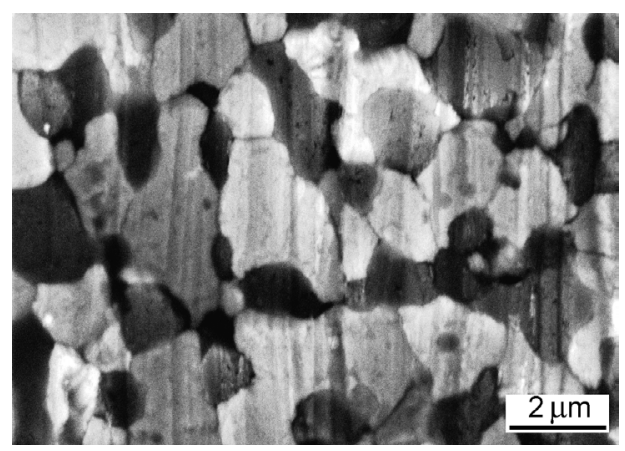

Fig. 4. The microstructure on the polished surface within the gauge length of a $\mathrm{Zn}-22 \% \mathrm{Al}$ alloy after ECAP and tested to an elongation of $30 \%$ at $10^{-2} \mathrm{~s}^{-1}$ at $473 \mathrm{~K}$ where the tensile axis is vertical $[27,28]$.

elongation of $30 \%$ at $1.0 \times 10^{-2} \mathrm{~s}^{-1}$ : the grains appearing white are the $\mathrm{Zn}$-rich grains and the grains appearing dark are the Al-rich grains. Thus, there is a clear shift in the marker lines applied prior to testing in the microstructure shown in fig.4 thereby demonstrating the occurrence of GBS under these testing conditions. It is worth noting that a further grain refinement to $\sim 350 \mathrm{~nm}$ may be attained in the $\mathrm{Zn}-22 \% \mathrm{Al}$ alloy through HPT processing and, as anticipated from eq. (1), high strain rate superplasticity with a maximum elongation of $\sim 1800 \%$ was observed at the faster strain rate of $1.0 \times 10^{-1} \mathrm{~s}^{-1}[30,31]$.

Grain refinement through SPD processing leads to the development of optimal superplastic conditions. Recent reports showed that superplastic flow behavior in UFG metals is consistent with the conventional theoretical mechanism for superplastic flow $[32,33]$. In practice, the experimental datum points after tensile testing may be plotted in the form of a temperature and grain size compensated strain rate versus normalized stress and the results are shown in fig. 5 for a series of UFG Al alloys after processing by (a) ECAP [32] and (b) HPT [33] where details of the references are given in [25,3440] for ECAP and [41-48] for HPT. In fig.5 the predicted strain rate for superplasticity controlled by GBS is also shown

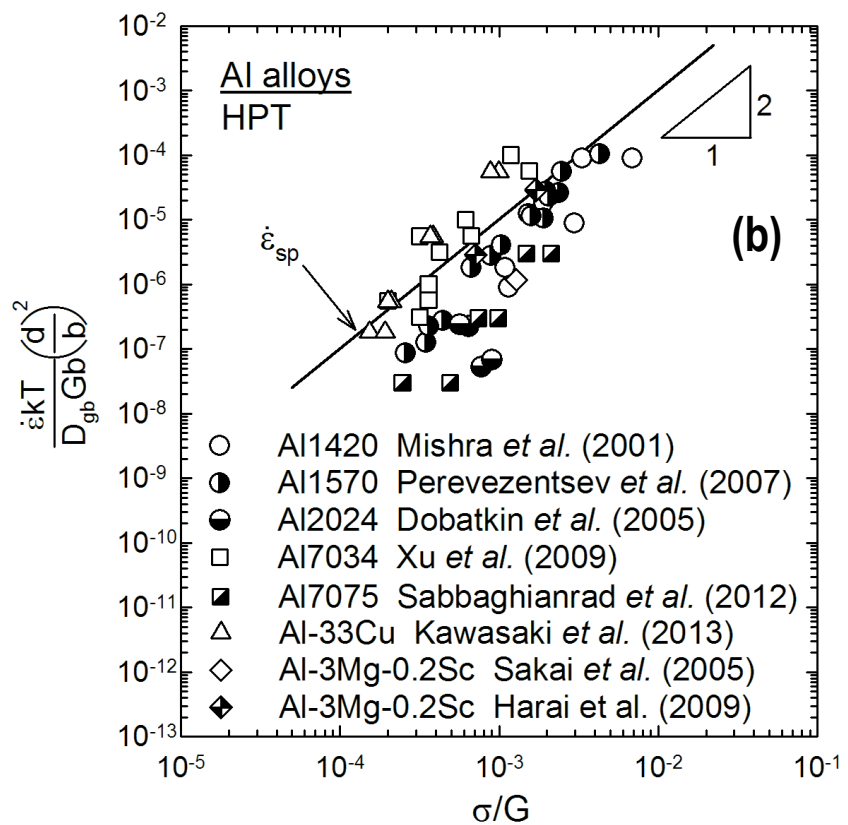

Fig. 5. Temperature and grain size compensated strain rate versus the normalized stress for various Al alloys processed by (a) ECAP [32] and (b) HPT [33] exhibiting superplastic behavior where details of the references are given in [25,34-40] for ECAP and [41-48] for HPT: the solid line shows the theoretical prediction for superplastic flow in conventional metals without SPD processing [8]. 
where the prediction was obtained by using eq. (1) and taking $n=2, p=2, Q=Q_{\mathrm{gb}}$ and $A=10$. It is readily apparent that the predicted theoretical lines are in excellent agreement with the experimental datum points, thereby confirming that the UFG materials processed by SPD procedures behave in a manner which is consistent with conventional superplastic alloys.

\section{The application of SPD processing to difficult to work alloys}

The use of SPD to refine the grain structure is also effective when processing difficult to work alloys. For example, early attempts to process magnesium and its alloys by ECAP were carried out at high temperatures and this was not effective for achieving grain refinement [49]. In order to overcome these initial difficulties to process magnesium alloys, alternative processing routes were developed such as EX-ECAP (extrusion followed by ECAP) [50,51] and increasing the angle of the ECAP die $[52,53]$. A different mechanism for grain refinement in magnesium alloys was proposed [54,55] and multiple reports in the literature agree with this model. Significant grain refinement has been reported for several different magnesium alloys to date.

It is readily apparent that the grain refinement introduced by ECAP in magnesium alloys provides the potential for achieving superplastic deformation. For example, a commercial extruded AZ31 alloy with an average linear intercept grain size of $\sim 9.1 \mu \mathrm{m}$ was processed by ECAP leading to grain refinement to an average grain size of $\sim 2.2 \mu \mathrm{m}$ [56]. Grain growth takes place in this alloy when heated to the temperature range of $623-723 \mathrm{~K}$ but the material processed by SPD remains with a finer grain structure compared to its counterpart processed only by extrusion. High temperature testing revealed that the material processed by SPD exhibits a strain rate sensitivity in the range of $\sim 0.5$ at strain rates of $10^{-5}-10^{-3} \mathrm{~s}^{-1}$ in this temperature range. This result agrees with the expected stress exponent for grain boundary sliding where $n=2$ in eq. (1). Also, it was shown that the activation energy for tests in this range of strain rate and temperature agrees with the expected activation energy for grain boundary diffusion in magnesium [56]. A recent report showed that the experimental data for superplasticity in a magnesium alloy agrees well with the predicted inverse grain size exponent of $p=2$ in eq. (1) [57].

Figure 6 shows a plot of experimental data of temperature and grain size compensated strain rate versus normalized stress for the magnesium AZ31 alloy [56,58,59]. The experimental data agree well with each other in the normalized stress range of $10^{-4}-10^{-3}$. Also, the theoretical line predicted by the equation for creep by superplasticity is also shown and this line agrees well with the experimental data for superplasticity in magnesium processed by ECAP.

\section{The significance of cavitation in superplasticity}

The high elongations observed in superplastic materials are attributed to the high strain rate sensitivity in these materials that prevent necking during deformation. The elongation is usually only limited by the formation and coalescence of internal cavities in the structure. There are three basic mechanisms of cavity growth during high temperature creep: (1) diffusion growth, (2) grain boundary diffusion growth and (3) plasticity-controlled growth. Diffusion growth is due to the diffusion of vacancies into the cavity and it is considered the major cavity growth mechanism for small cavities [60]. Grain boundary diffusion growth is caused by the accelerated rate of diffusion of vacancies through multiple grain boundaries that intercept a cavity [61]. This latter mechanism plays a key role when the cavity size is larger than, at least, one-half of the grain size. The plasticity growth mechanism is caused by the plastic deformation of the crystalline lattice surrounding the cavity and this plays a major role when the cavities are large [62].

When materials deform in superplastic flow, it is well known that there is invariably the occurrence of extensive internal cavitation with the cavities lying in stringers aligned essentially parallel to the tensile axis [63]. There have been several reports describing the development of internal cavitation in samples processed by ECAP using both conventional microscopy [38,64-70] and X-ray microtomography [71]. An example of the development of internal cavities is given in fig.7 where the fracture tips after tensile testing at $673 \mathrm{~K}$ are shown for (a) an as-received Al-7034 alloy which failed at an elongation of $550 \%$ and (b) an Al-7034 alloy processed by ECAP at $473 \mathrm{~K}$ for 6 passes and then pulled to failure at an elongation of $1085 \%$ [68]. It is apparent in both specimens that there are numbers of cavities aligned in stringers along the tensile axes. However, the appearance of the two specimens is different because the as-received alloy in fig.7a shows clear evidence of necking leading to premature failure whereas the specimen processed by ECAP in fig.7b shows the occurrence of abrupt failure through cavity interlinkage without any macroscopic necking.

In terms of the shapes of cavities, when cavies develop in superplasticity at high temperatures there is a significant difference depending upon the growth mechanism of the cavities. For the diffusion growth mechanism, the cavities

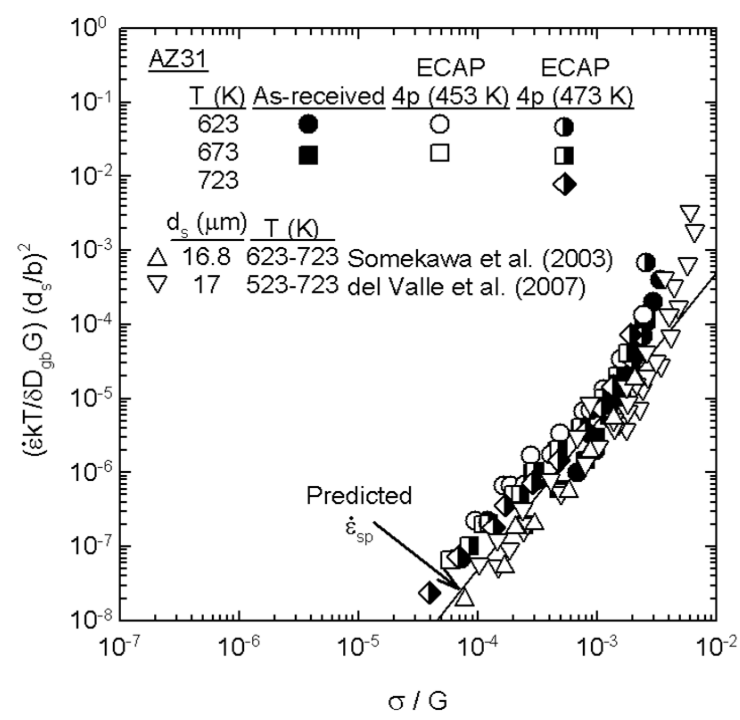

Fig. 6. Temperature and grain size compensated strain rate plotted as a function of normalized stress for the magnesium AZ31, including theoretical prediction for superplastic flow and data from the literature $[56,58,59]$. 


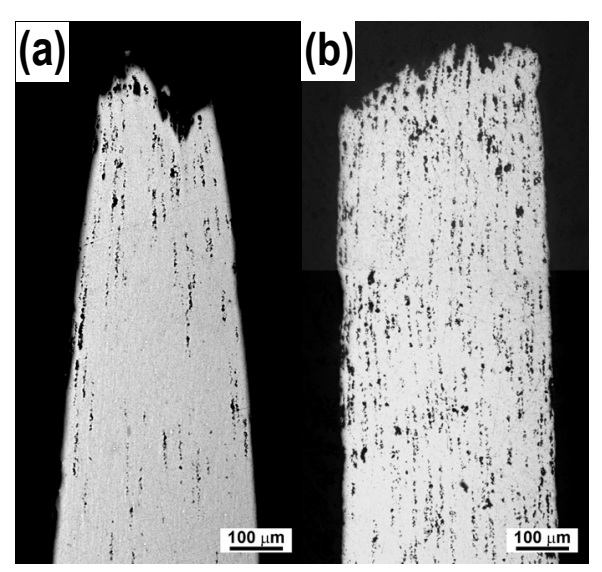

Fig. 7. Appearance of the fracture tips of specimens after tensile testing at $673 \mathrm{~K}$ at a strain rate of $1.0 \times 10^{-2} \mathrm{~s}^{-1}$ for (a) an as-received Al-7034 alloy and (b) an Al-7034 alloy processed by ECAP at $473 \mathrm{~K}$ for 6 passes [68].

have a rounded appearance and the roundness coefficient, defined as $\{4 \pi \times$ cavity area $\} /(\text { perimeter })^{2}$, is close to 1.0 denoting a circular cross-section for the cavity. By contrast, for the plasticity-controlled growth mechanism the cavities become elongated along the tensile axis and the roundness coefficient is $<1.0$ and there are deviations from a circular shape. Several recent quantitative measurements demonstrated that the smallest and round cavities grow by diffusion whereas the largest and elongated cavities exhibit plasticity-controlled growth during superplastic flow in metals processed by ECAP [57,67-72].

Experiments have shown that cavity growth in materials processed by SPD agrees with the theoretical models for cavity growth in materials with conventional grain sizes [63]. The rate of growth of cavities tends to increase with increasing stress imposed on the material during creep. An analysis of the equation for the creep strain rate during superplastic deformation reveals that the exponents $p$ and $n$ in eq. (1) are

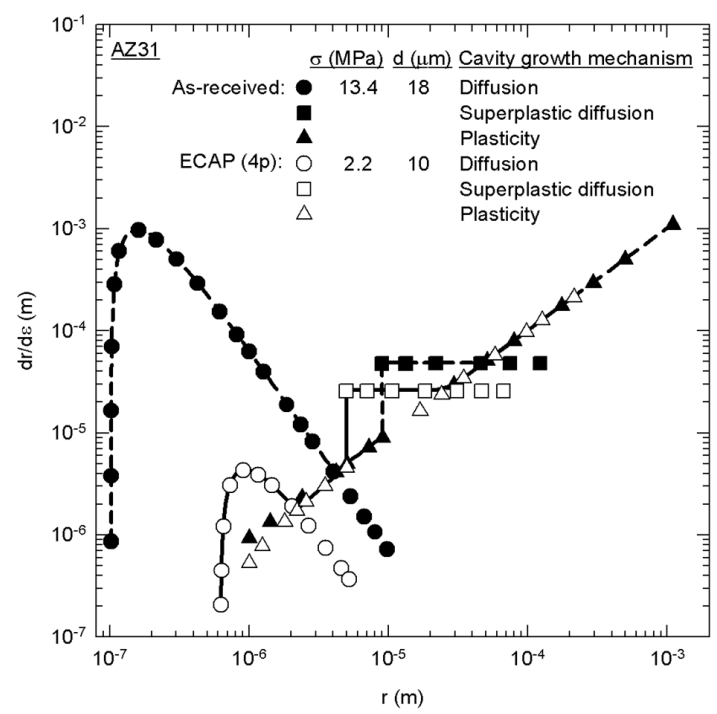

Fig. 8. Cavity growth rate plotted as a function of the cavity radius for magnesium AZ31 alloy in the extruded condition and after ECAP processing considering the different cavity growth mechanisms [71]. both equal to 2 . Therefore, decreasing the grain size leads to a reduction of the flow stress for the same strain rate of deformation and this affects the rate of cavity growth. Figure 8 shows a plot of the predicted rate of cavity growth plotted as a function of the cavity radius, $r$, considering the three mechanisms of cavity growth for a magnesium AZ31 alloy with different grain sizes [71]. The experiments showed that the stress obtained during deformation of the material processed by ECAP is lower than the stress observed in its counterpart which was not processed by SPD. As a consequence of the lower imposed stress, the rate of cavity growth in the material processed by ECAP is lower than the rate of growth in the conventional as-received material [71]. This explains the higher elongations observed in materials processed by ECAP compared to similar materials with conventional grain structures.

The absence of necking in superplastic metals means that in practice attention must be given to the nucleation, growth and interlinkage of these internal cavities because the final failure will depend upon the rate of cavity interlinkage. An earlier review of the fracture processes in superplastic flow [63] provides a comprehensive summary of the various types of failure that occur in these materials.

\section{Summary and conclusions}

1. Superplastic elongations may be attained in metals with small grain sizes, typically $<10 \mu \mathrm{m}$, when testing in tension at temperatures above $\sim 0.5 T_{\mathrm{m}}$ where $T_{\mathrm{m}}$ is the absolute melting temperature.

2. Processing through the application of severe plastic deformation (SPD) produces even smaller grain sizes, typically in the submicrometer or the nanometer range, and these materials provide a capability for producing excellent superplastic properties at exceptionally rapid strain rates.

3. The ultrafine-grained materials produced by SPD processing exhibit superplastic strain rates and cavitation characteristics which are similar to the properties observed in conventional superplastic alloys having grain sizes which are larger by, typically, about one order of magnitude.

This work was supported in part by the research fund of Hanyang University (HY-2013) (MK), in part by Brazilian National Research Counsil (CNPq), FAPEMIG and CAPES $(R B F)$, in part by the National Science Foundation of the United States under Grant No. DMR-1160966 and in part by the European Research Council under ERC Grant Agreement No. 267464-SPDMETALS (TGL).

\section{References}

1. A. J. Barnes. J. Mater. Eng. Perform. 16, 440 (2007).

2. T. G. Langdon. J. Mater. Sci. 49, 5998 (2009).

3. C.E. Pearson. J. Inst. Metals. 54, 111 (1934).

4. Y. Ma, T.G. Langdon. Metall. Mater. Trans. 25A, 2309 (1994).

5. T. G. Langdon. Mater. Sci. Eng. A174, 225 (1994).

6. F. A. Mohamed, T. G. Langdon. Scr. Metall. 10, 759 (1976).

7. L.K.L. Falk, P. R. Howell, G. L. Dunlop, T. G. Langdon. Acta Metall. 34, 1203 (1986). 
8. R.Z. Valiev, T.G. Langdon. Acta Metall. Mater. 41, 949 (1993).

9. Y. Xun, F. A. Mohamed. Phil. Mag. 83, 2247 (2003).

10. Y. Xun, F. A. Mohamed. Acta Mater. 52, 4401 (2004).

11. T. G. Langdon. Metall. Trans. 13A, 689 (1982).

12. T. G. Langdon. Metall. Mater. Trans. 33A, 249 (2002).

13. T. G. Langdon. Z. Metallk. 96, 522 (2005).

14. T. G. Langdon. Acta Metall. Mater. 42, 2437 (1994).

15. D. A. Woodford. Trans. ASM. 62, 291 (1969).

16. F. A. Mohamed, M. M. I. Ahmed, T. G. Langdon. Metall. Trans. 8A, 933 (1977).

17. M. M. I. Ahmed, T. G. Langdon. Metall. Trans. 8A, 1832 (1977).

18. H. Ishikawa, F. A. Mohamed, T. G. Langdon. Phil. Mag. 32, 1269 (1975).

19. J. Weertman. J. Appl. Phys. 28, 362 (1957).

20. R.Z. Valiev, R. K. Islamgaliev, I. V. Alexandrov. Prog. Mater. Sci. 45, 103 (2000).

21. R.Z. Valiev, Y. Estrin, Z. Horita, T.G. Langdon, M. J. Zehetbauer, Y. T. Zhu. JOM. 58(4), 33 (2006).

22. T. G. Langdon. Acta Mater. 61, 7035 (2013).

23. R.Z. Valiev, T.G. Langdon. Prog. Mater. Sci. 51, 881 (2006).

24. A.P. Zhilyaev, T. G. Langdon. Prog. Mater. Sci. 53, 893 (2008).

25. R. K. Islamgaliev, N. F. Yunusova, R. Z. Valiev, N. K. Tsenev, V.N. Perevezentsev, T.G. Langdon. Scr. Mater. 49, 467 (2003).

26. P. Kumar, C. Xu, T. G. Langdon. Mater. Sci. Eng. A410411, 447 (2005).

27. M. Kawasaki, T. G. Langdon. Mater. Trans. 49, 84 (2008).

28. M. Kawasaki, T. G. Langdon. J. Mater. Sci. 48, 4730 (2013).

29. K. Higashi, M. Mabuchi, T. G. Langdon. ISIJ Intl. 36, 1423 (1996).

30. M. Kawasaki, T. G. Langdon. Mater. Sci.Eng. A528, 6140 (2011).

31. T-S. Cho, H-J. Lee, B. Ahn, M. Kawasaki, T. G. Langdon. Acta Mater. 72, 67 (2014).

32. M. Kawasaki, N. Balasubramanian, T. G. Langdon. Mater. Sci. Eng. A528, 6624 (2010).

33. M. Kawasaki. T. G. Langdon. J. Mater. Sci. 49, 6487 (2014).

34. R. Z. Valiev, D. A. Salimonenko, N. K. Tsenev, P. B. Berbon, T. G. Langdon. Scr. Mater. 37, 1945 (1997).

35. S. Komura, M. Furukawa, Z. Horita, M. Nemoto, T. G. Langdon. Mater. Sci. Eng. A297, 111 (2001).

36. S. Komura, Z. Horita, M. Furukawa, M. Nemoto, T. G. Langdon. Metall. Mater. Trans. A. 32A, 707 (2001).

37. K.-T. Park, D. Y. Hwang, Y. K. Lee, Y. K. Kim, D. H. Shin. Mater. Sci.Eng. A341, 273 (2003).

38. F. Musin, R. Kaibyshev, Y. Motohashi, G. Itoh. Metall. Mater. Trans. A. 35A, 2383 (2004).

39. S. Lee, A. Utsunomiya, H. Akamatsu, K. Neishi, M. Furukawa, Z. Horita, T. G. Langdon. Acta Mater. 50, 553 (2005).

40. I. Nikulin, R. Kaibyshev, T. Sakai. Mater. Sci. Eng. A407, 62 (2005).

41. R. S. Mishra, R. Z. Valiev, S. X. McFadden, R. K. Islamgaliev, A. K. Mukherjee. Phil. Mag. A. 81, 37 (2001).

42. G. Sakai, Z. Horita, T. G. Langdon. Mater. Sci. Eng. A393, 344 (2005).
43. S. V. Dobatkin, E. N. Bastarache, G. Sakai, T. Fujita, Z. Horita, T.G. Langdon. Mater. Sci.Eng. A408, 141 (2005).

44. V. N. Perevezentsev, M. Yu. Shcherban, M. Yu. Murashkin, R.Z. Valiev. Tech. Phys. Lett. 33, 648 (2007).

45. Y. Harai, K. Edalati, Z. Horita, T. G. Langdon. Acta Mater. 57, 1147 (2009).

46. C. Xu, S. V. Dobatkin, Z. Horita, T. G. Langdon. Mater. Sci. Eng. A500, 170 (2009).

47. S. Sabbaghianrad, M. Kawasaki, T. G. Langdon. J. Mater. Sci. 47, 7789 (2012).

48. M. Kawasaki, J. Foissey, T.G. Langdon. Mater. Sci. Eng. A561, 118 (2013).

49. A. Yamashita, Z. Horita, T. G. Langdon. Mater. Sci. Eng. A. 300, 142 (2001).

50. Z. Horita, K. Matsubara, K. Makii, T. G. Langdon. Scr. Mater. 47, 255 (2002).

51. K. Matsubara, Y. Miyahara, Z. Horita, T. G. Langdon. Acta Mater. 51, 3073 (2003).

52. M. Furui, H. Kitamura, H. Anada, T. G. Langdon. Acta Mater. 55, 1083 (2007).

53. R. B. Figueiredo, P. R. Cetlin, T. G. Langdon. Acta Mater. 55, 4769 (2007).

54. R. B. Figueiredo, T. G. Langdon. J. Mater. Sci. 44, 4758 (2009).

55. R. B. Figueiredo, T. G. Langdon. J. Mater. Sci. 45, 4827 (2010).

56. R. B. Figueiredo, T. G. Langdon. J. Mater. Sci. 43, 7366 (2008).

57. R. B. Figueiredo, T. G. Langdon. Metal. Mater. Trans. A 45A, 3197 (2014).

58. H. Somekawa, H. Hosokawa, H. Watanabe, K. Higashi. Mater. Sci. Eng. A339, 328 (2003).

59. J. A. del Valle, F. Carreño, O. A. Ruano. Scr. Mater. 57, 829 (2007).

60. M. V. Speight, W. Beere. Metal Sci. 9, 190 (1975).

61. A.H. Chokshi, T.G. Langdon. Acta Metall. 35, 1089 (1987).

62. J. W. Hancock. Metal Sci. 10, 319 (1976).

63. T. G. Langdon. Metal Sci. 16, 175 (1982).

64. K. Neishi, T. Uchida, A. Yamauchi, K. Nakamura, Z. Horita, T.G. Langdon. Mater. Sci.Eng. A307, 2328 (2001).

65. K.-T. Park, S.H. Myung, D. H. Shin, C.S. Lee. Mater. Sci. Eng. A371, 1781 (2004).

66. F. Musin, R. Kaibyshev, Y. Motohashi, G. Itoh. Scr. Mater. 50, 511 (2004).

67. M. Kawasaki, Y. Huang, C. Xu, M. Furukawa, Z. Horita, T. G. Langdon. Mater. Sci. Eng. A410-411, 402 (2005).

68. M. Kawasaki, C. Xu, T. G. Langdon. Acta Mater. 53, 5353 (2005).

69. M. Kawasaki, T. G. Langdon. J. Mater. Sci. 43, 7360 (2008).

70. M. Kawasaki, T. G. Langdon. Mater. Trans. 53, 87 (2012).

71. R. B. Figueiredo, S. Terzi, T. G. Langdon. Acta Mater. 58, 5737 (2010).

72. R. B. Figueiredo, T.G. Langdon. Mater. Sci.Eng. A556, 211 (2012). 